\title{
Determination of Stroke Volume from Left Ventricular Isovolumetric Contraction and Ejection Times
}

\author{
Glarence M. Agress, M.D. \\ and Stanley Wegner
}

\begin{abstract}
Summary
Examination was made of the relationship of left ventricular isovolumetric contraction and ejection times to stroke volume. These studies were performed in humans at cardiac catheterization using the dye dilution technique and in open-chest dogs with electromagnetic flowmeters. The cardiac phases were measured from intracardiac catheters in humans and were calculated from the flow curves in dogs. While the isovolumetric and ejection periods independently gave correlations of only marginal significance with stroke volume, the ratio of these intervals was highly significant: $r=0.92$ for humans and $r=0.86$ for dogs.
\end{abstract}

\section{Additional Indexing Words :}

Cardiac phases Indirect cardiac output

7 HE relationship between stroke volume and the systolic phases of ventricu1 lar contraction "was first implied in the frog heart studies of Otto Frank. ${ }^{1)}$ Subsequent investigations in animal and man have provided evidence that the cjection phase of ventricular systole, under conditions of uniform myocardial contractility, is directly related to stroke volume. ${ }^{2-9)}$ These investigators also recognized the inverse relationship between the isovolumetric contraction interval and stroke volume. Blumberger ${ }^{10}$ reported that a ratio of the ejection and isovolumetric contraction periods reflected changes in stroke volume, but his work was not substantiated by direct stroke volume measurements. In 1965, a report from our laboratory described the use of the systolic intervals for determining stroke volume in dogs. ${ }^{11}$ The present investigation was undertaken to determine whether the durations of the isovolumetric contraction and ejection intervals, independently or in combination, could be used to estimate stroke volume.

From the Cedars-Sinai Medical Research Institute Los Angeles, California.

This study was supported by Grant \#NsG-289/05-12-001 from National Aeronautics and Space Administration.

Received for publication March 18, 1968. 


\section{METHODS}

\section{Human Experiments}

Data were obtained from 25 subjects who had undergone left heart catheterization and who fulfilled the following criteria of normal left heart hemodynamics: sinus rhythm, normal blood pressure, normal end-diastolic pressure, absence of valvular insufficiency and shunts. Patients with minimal aortic stenosis were included if the gradient was less than $10 \mathrm{~mm}$. Hg. In 9 of these subjects, simultaneous left ventricular and aortic pressures and ECGs were inscribed on a Honeywell oscillographic recorder, at a paper speed of $100 \mathrm{~mm}$. $/ \mathrm{sec}$. In the remaining 16 subjects, ECGs and central aortic pressure tracings were obtained immediately after the catheter was withdrawn from the left ventricle. The isovolumetric contraction period was measured from the R peak of the ECG to the aortic upstroke; the ejection interval was measured from the aortic upstroke to the incisura of the dicrotic notch. Cardiac outputs were performed using cardio-green dye and the Stewart-Hamilton formula used for computation.

\section{Animal Experiments}

Five open-chest normotensive dog experiments were performed using a Statham pulsed-field electromagnetic flowmeter placed at the aortic root ${ }^{2}$. The flowmeter was calibrated with each animal's blood and the instrument calibration was maintained the same in all experiments. The flow curves and Lead II of the ECG were recorded on an Electronics for Medicine oscillographic recorder at a speed of 200 $\mathrm{mm} . / \mathrm{sec}$.

Measurements of the isovolumetric contraction interval were made from the peak of the " $R$ " wave to the onset of the flowmeter upstroke; the ejection period was measured by the duration of the flow curve. Stroke volumes were calculated by measuring the area under the flow curves transcribed to $\mathrm{mm} .{ }^{2}$ paper using the "counting squares" method. Hemodynamic alterations were accomplished by rapid infusion of $100 \mathrm{ml}$. of blood into the right atrium and by mechanical constriction of the aortic arch, just distal to the site of the flowmeter.

Regression analyses were performed on the data to determine the best-fit formula for estimating stroke volume from the cardiac phases.

\section{RESULTS}

\section{Human}

The data consisted of 30 measurements made in 25 subjects and are listed in Table $I$.

The relationship between the ejection intervals (ET) and stroke volume

1. We wish to express our gratitude to Dr. Jeremy Swan, formerly at Mayo Clinic and now Chief of Cardiology at Cedars-Sinai Medical Center, Los Angeles, California, and to Dr. Donald Ritter at Mayo Clinic, Rochester, Minnesota, for cases 1-9; Dr. Oscar Magidson at St. Vincent's Hospital, Los Angeles, California for cases 10-16; Dr. Morton Lee Pierce at Veterans Administration Hospital, Los Angeles, California for cases 17-25.

2. Statham pulsed-field electromagnetic flowmeter Model 0-5000. 
(SV) is illustrated in Fig. 1-a. While there is a tendency for the ejection period to be prolonged at higher stroke volumes, no consistent relationship between these parameters is evident $(r=0.14)$. A significant inverse relationship $(\mathrm{r}=0.74)$ was found between the isovolumetric contraction interval $(\mathrm{ICT})$ and SV (Fig. 1-b).

The comparison of the ET/ICT ratio to SV is shown in Fig. 2. A direct relationship was found with a significantly improved correlation over ICT or ET independently $(r=0.92)$.

Table I. Human Data

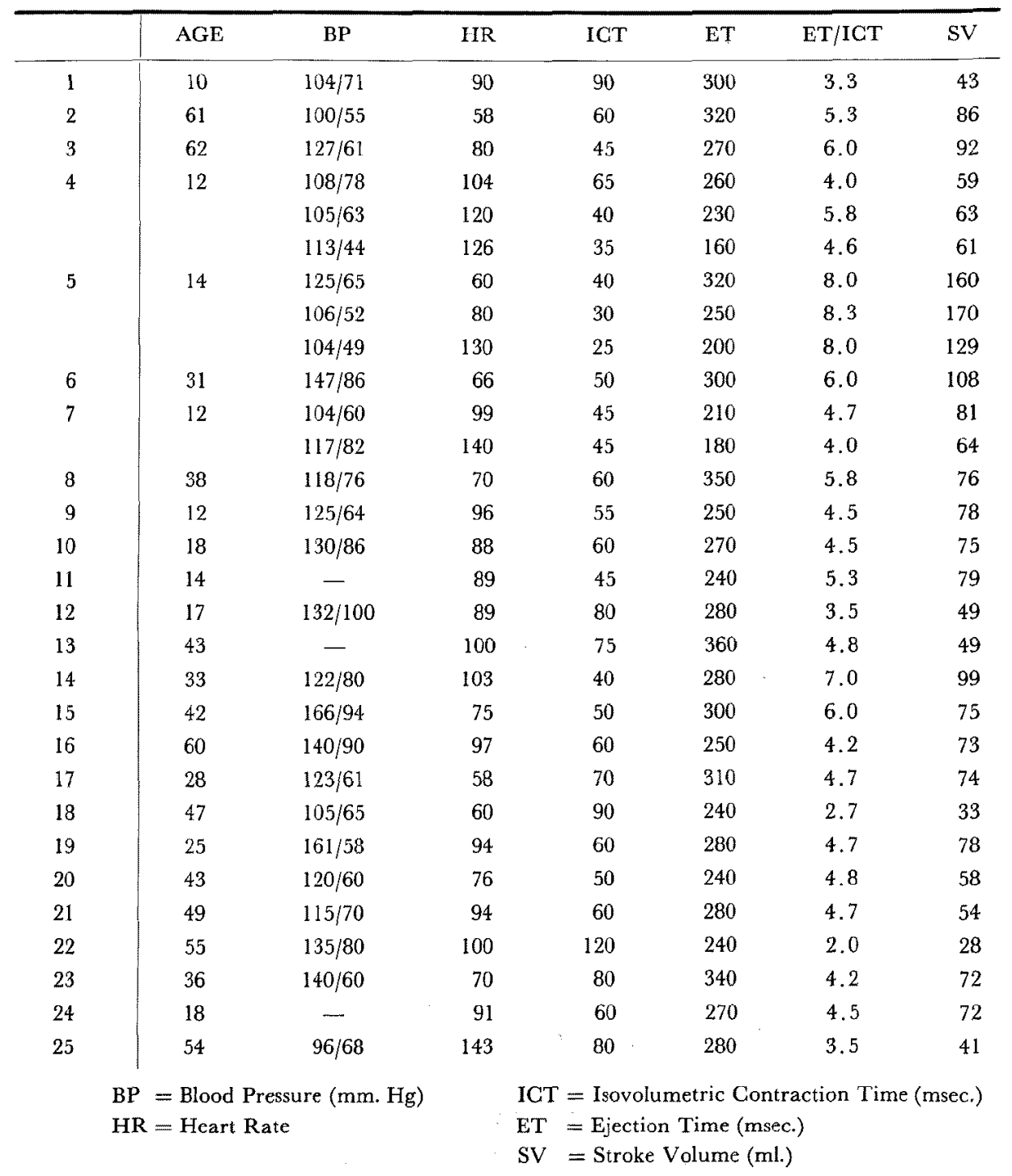



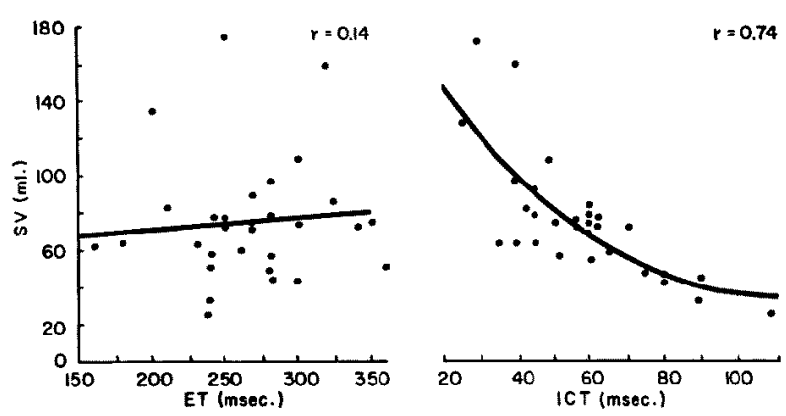

Fig. 1. In the human, ET was virtually independent of SV, while ICT had a significant inverse relationship.

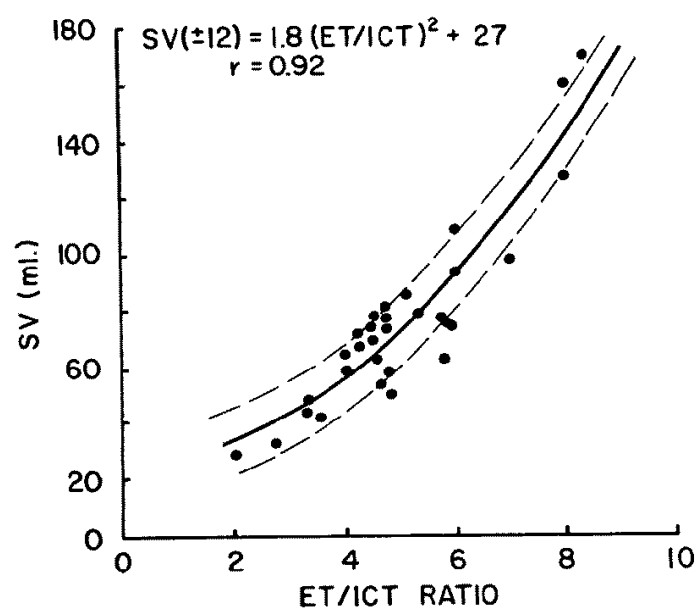

Fig. 2. The ratio ET/ICT had a significantly improved correlation with SV over the intervals independently. The parabola has its minimum at the $\mathrm{Y}$-axis resulting in no linear term in the equation.

Fig. 3 compares the measured and estimated stroke volumes based on the regression formula:

$$
\mathrm{SV}=1.8(\mathrm{ET} / \mathrm{ICT})^{2}+27
$$

Most of the predicted stroke volumes fall within $20 \%$ of the actual stroke volumes and are equally distributed about the line of identity. The difference between measured and estimated stroke volume and heart rate (Fig. 4-a) indicated that the stroke volume estimate was not significantly influenced by heart rate. Similar observations were made on the arterial pressure (Fig. 4-b).

Animal

The data from the 5 dog experiments, comprising 100 stroke volume and cardiac interval measurements are listed in Table II. 
Table II. Animal Data

\begin{tabular}{|c|c|c|c|c|c|c|c|c|c|c|c|}
\hline SV & ICT & $\mathrm{ET}$ & ET/ICT & $\mathrm{HR}$ & $\mathrm{SP}$ & SV & ICT & $\mathrm{ET}$ & $\mathrm{ET} / \mathrm{ICT}$ & HR & SP \\
\hline $\begin{array}{l}3.4 \\
4.1 \\
4.2 \\
4.4 \\
6.3\end{array}$ & $\begin{array}{l}45 \\
65 \\
65 \\
60 \\
50\end{array}$ & $\begin{array}{l}120 \\
110 \\
110 \\
115 \\
125\end{array}$ & $\begin{array}{l}2.7 \\
1.7 \\
1.7 \\
1.9 \\
2.5\end{array}$ & $\begin{array}{l}140 \\
188 \\
170 \\
166 \\
166\end{array}$ & $\begin{array}{l}69 \\
70 \\
75 \\
76 \\
76\end{array}$ & $\begin{array}{l}3.0 \\
3.0 \\
3.5 \\
4.3 \\
4.3\end{array}$ & $\begin{array}{l}75 \\
75 \\
72 \\
72 \\
65\end{array}$ & $\begin{array}{l}105 \\
100 \\
105 \\
110 \\
115\end{array}$ & $\begin{array}{l}1.4 \\
1.3 \\
1.5 \\
1.5 \\
1.8\end{array}$ & $\begin{array}{l}180 \\
180 \\
180 \\
160 \\
165\end{array}$ & $\begin{array}{l}83 \\
83 \\
91 \\
97 \\
97\end{array}$ \\
\hline $\begin{array}{l}6.8 \\
6.9 \\
7.2 \\
7.3 \\
7.4\end{array}$ & $\begin{array}{l}50 \\
55 \\
47 \\
47 \\
52\end{array}$ & $\begin{array}{l}170 \\
160 \\
170 \\
160 \\
165\end{array}$ & $\begin{array}{l}3.4 \\
2.9 \\
3.6 \\
3.4 \\
3.2\end{array}$ & $\begin{array}{l}145 \\
136 \\
140 \\
133 \\
133\end{array}$ & $\begin{array}{l}76 \\
70 \\
77 \\
90 \\
76\end{array}$ & $\begin{array}{l}4.5 \\
4.7 \\
4.8 \\
5.2 \\
5.4\end{array}$ & $\begin{array}{l}60 \\
60 \\
75 \\
65 \\
62\end{array}$ & $\begin{array}{l}125 \\
125 \\
120 \\
115 \\
125\end{array}$ & $\begin{array}{l}2.1 \\
2.1 \\
1.6 \\
1.8 \\
2.0\end{array}$ & $\begin{array}{l}165 \\
165 \\
160 \\
165 \\
165\end{array}$ & $\begin{array}{l}94 \\
90 \\
97 \\
97 \\
97\end{array}$ \\
\hline $\begin{array}{l}7.4 \\
8.0 \\
8.0 \\
8.3 \\
9.3\end{array}$ & $\begin{array}{l}45 \\
45 \\
50 \\
47 \\
50\end{array}$ & $\begin{array}{l}175 \\
170 \\
160 \\
175 \\
180\end{array}$ & $\begin{array}{l}3.9 \\
3.8 \\
3.2 \\
3.7 \\
3.6\end{array}$ & $\begin{array}{l}133 \\
133 \\
130 \\
133 \\
133\end{array}$ & $\begin{array}{l}80 \\
76 \\
75 \\
85 \\
76\end{array}$ & $\begin{array}{l}2.0 \\
2.2 \\
2.4 \\
2.7 \\
4.0\end{array}$ & $\begin{array}{l}70 \\
80 \\
70 \\
65 \\
75\end{array}$ & $\begin{array}{l}135 \\
137 \\
135 \\
140 \\
150\end{array}$ & $\begin{array}{l}1.9 \\
1.9 \\
1.7 \\
1.9 \\
2.2\end{array}$ & $\begin{array}{l}140 \\
133 \\
145 \\
140 \\
140\end{array}$ & \\
\hline $\begin{array}{l}10.0 \\
10.2 \\
10.6 \\
10.8 \\
11.0\end{array}$ & $\begin{array}{l}45 \\
45 \\
45 \\
42 \\
45\end{array}$ & $\begin{array}{l}170 \\
170 \\
175 \\
180 \\
170\end{array}$ & $\begin{array}{l}3.8 \\
3.8 \\
3.9 \\
4.3 \\
3.8\end{array}$ & $\begin{array}{l}133 \\
136 \\
130 \\
185 \\
133\end{array}$ & $\begin{array}{r}94 \\
110 \\
85 \\
85 \\
110\end{array}$ & $\begin{array}{l}4.2 \\
5.3 \\
5.3 \\
5.4 \\
5.7\end{array}$ & $\begin{array}{l}67 \\
60 \\
55 \\
56 \\
65\end{array}$ & $\begin{array}{l}150 \\
150 \\
160 \\
154 \\
165\end{array}$ & $\begin{array}{l}2.3 \\
2.5 \\
2.9 \\
2.7 \\
2.3\end{array}$ & $\begin{array}{l}130 \\
140 \\
140 \\
133 \\
133\end{array}$ & \\
\hline $\begin{array}{l}4.8 \\
4.8 \\
5.0 \\
5.4 \\
5.5\end{array}$ & $\begin{array}{l}70 \\
65 \\
70 \\
55 \\
65\end{array}$ & $\begin{array}{l}160 \\
175 \\
150 \\
175 \\
165\end{array}$ & $\begin{array}{l}2.3 \\
2.7 \\
2.1 \\
3.2 \\
2.5\end{array}$ & $\begin{array}{l}135 \\
140 \\
140 \\
127 \\
145\end{array}$ & $\begin{array}{r}70 \\
63 \\
100 \\
90 \\
110\end{array}$ & $\begin{array}{l}5.7 \\
5.7 \\
6.2 \\
6.5 \\
6.5\end{array}$ & $\begin{array}{l}55 \\
55 \\
50 \\
50 \\
55\end{array}$ & $\begin{array}{l}165 \\
170 \\
155 \\
170 \\
170\end{array}$ & $\begin{array}{l}3.0 \\
3.1 \\
2.8 \\
3.4 \\
3.1\end{array}$ & $\begin{array}{l}130 \\
133 \\
140 \\
140 \\
133\end{array}$ & \\
\hline $\begin{array}{l}5.6 \\
5.7 \\
5.7 \\
5.7 \\
5.8\end{array}$ & $\begin{array}{l}55 \\
60 \\
60 \\
62 \\
60\end{array}$ & $\begin{array}{l}170 \\
160 \\
165 \\
185 \\
185\end{array}$ & $\begin{array}{l}3.1 \\
2.7 \\
2.8 \\
3.0 \\
3.1\end{array}$ & $\begin{array}{l}143 \\
143 \\
143 \\
143 \\
127\end{array}$ & $\begin{array}{l}134 \\
134 \\
120 \\
126 \\
120\end{array}$ & $\begin{array}{r}6.5 \\
6.5 \\
7.0 \\
9.0 \\
11.8\end{array}$ & $\begin{array}{l}50 \\
50 \\
54 \\
51 \\
41\end{array}$ & $\begin{array}{l}170 \\
170 \\
174 \\
185 \\
180\end{array}$ & $\begin{array}{l}3.4 \\
3.4 \\
3.2 \\
3.6 \\
4.4\end{array}$ & $\begin{array}{l}133 \\
135 \\
128 \\
130 \\
130\end{array}$ & \\
\hline $\begin{array}{l}6.0 \\
6.2 \\
6.2 \\
6.2 \\
6.5\end{array}$ & $\begin{array}{l}60 \\
55 \\
60 \\
60 \\
57\end{array}$ & $\begin{array}{l}170 \\
175 \\
185 \\
185 \\
190\end{array}$ & $\begin{array}{l}2.8 \\
3.2 \\
3.1 \\
3.1 \\
3.3\end{array}$ & $\begin{array}{l}143 \\
127 \\
143 \\
145 \\
143\end{array}$ & $\begin{array}{l}134 \\
120 \\
120 \\
110 \\
126\end{array}$ & $\begin{array}{l}4.0 \\
4.3 \\
4.3 \\
4.5 \\
4.8\end{array}$ & $\begin{array}{l}75 \\
70 \\
70 \\
60 \\
70\end{array}$ & $\begin{array}{l}130 \\
140 \\
145 \\
150 \\
135\end{array}$ & $\begin{array}{l}1.7 \\
2.0 \\
2.1 \\
2.5 \\
1.9\end{array}$ & $\begin{array}{l}155 \\
175 \\
160 \\
155 \\
175\end{array}$ & $\begin{array}{l}80 \\
80 \\
80 \\
80 \\
80\end{array}$ \\
\hline $\begin{array}{l}6.5 \\
6.6 \\
6.6 \\
7.2 \\
8.0\end{array}$ & $\begin{array}{l}55 \\
50 \\
50 \\
55 \\
60\end{array}$ & $\begin{array}{l}175 \\
175 \\
170 \\
175 \\
170\end{array}$ & $\begin{array}{l}3.2 \\
3.5 \\
3.4 \\
3.2 \\
2.8\end{array}$ & $\begin{array}{l}132 \\
143 \\
120 \\
127 \\
132\end{array}$ & $\begin{array}{r}130 \\
134 \\
128 \\
90 \\
130\end{array}$ & $\begin{array}{l}5.0 \\
5.2 \\
5.3 \\
5.6 \\
6.3\end{array}$ & $\begin{array}{l}55 \\
70 \\
65 \\
50 \\
70\end{array}$ & $\begin{array}{l}130 \\
145 \\
150 \\
150 \\
145\end{array}$ & $\begin{array}{l}2.4 \\
2.1 \\
2.5 \\
3.0 \\
2.1\end{array}$ & $\begin{array}{l}150 \\
160 \\
160 \\
170 \\
160\end{array}$ & $\begin{array}{r}90 \\
90 \\
90 \\
105 \\
90\end{array}$ \\
\hline $\begin{array}{l}1.4 \\
1.5 \\
1.6 \\
1.8 \\
1.8\end{array}$ & $\begin{array}{l}80 \\
80 \\
75 \\
75 \\
70\end{array}$ & $\begin{array}{r}90 \\
90 \\
90 \\
100 \\
110\end{array}$ & $\begin{array}{l}1.1 \\
1.1 \\
1.2 \\
1.3 \\
1.6\end{array}$ & $\begin{array}{l}180 \\
180 \\
180 \\
180 \\
180\end{array}$ & $\begin{array}{l}63 \\
63 \\
63 \\
63 \\
63\end{array}$ & $\begin{array}{l}6.6 \\
6.8 \\
7.4 \\
7.5 \\
7.8\end{array}$ & $\begin{array}{l}60 \\
55 \\
52 \\
60 \\
50\end{array}$ & $\begin{array}{l}150 \\
150 \\
150 \\
150 \\
150\end{array}$ & $\begin{array}{l}2.5 \\
2.7 \\
2.9 \\
2.5 \\
3.0\end{array}$ & $\begin{array}{l}160 \\
170 \\
170 \\
175 \\
160\end{array}$ & $\begin{array}{r}97 \\
105 \\
110 \\
130 \\
134\end{array}$ \\
\hline $\begin{array}{l}2.0 \\
2.0 \\
2.6 \\
2.9 \\
3.0\end{array}$ & $\begin{array}{l}75 \\
75 \\
77 \\
70 \\
80\end{array}$ & $\begin{array}{r}110 \\
95 \\
100 \\
105 \\
110\end{array}$ & $\begin{array}{l}1.5 \\
1.3 \\
1.3 \\
1.5 \\
1.4\end{array}$ & $\begin{array}{l}180 \\
180 \\
180 \\
180 \\
180\end{array}$ & $\begin{array}{l}63 \\
63 \\
83 \\
85 \\
85\end{array}$ & $\begin{array}{r}8.1 \\
8.9 \\
9.1 \\
9.6 \\
10.0\end{array}$ & $\begin{array}{l}50 \\
70 \\
60 \\
50 \\
50\end{array}$ & $\begin{array}{l}150 \\
150 \\
160 \\
150 \\
150\end{array}$ & $\begin{array}{l}3.0 \\
2.3 \\
2.7 \\
3.0 \\
3.0\end{array}$ & $\begin{array}{l}170 \\
150 \\
160 \\
150 \\
160\end{array}$ & $\begin{array}{l}170 \\
130 \\
130 \\
130 \\
130\end{array}$ \\
\hline & \multicolumn{5}{|c|}{$\begin{array}{l}\mathrm{SV}=\text { Stroke Volume (ml.) } \\
\mathrm{ET}=\text { Ejection Time (msec.) }\end{array}$} & \multicolumn{6}{|c|}{$\begin{array}{l}\text { ICT }=\text { Isovolumetric C } \\
\mathrm{HR}=\text { Heart Rate } \\
\mathrm{SP}=\text { Systolic Pressure }\end{array}$} \\
\hline
\end{tabular}




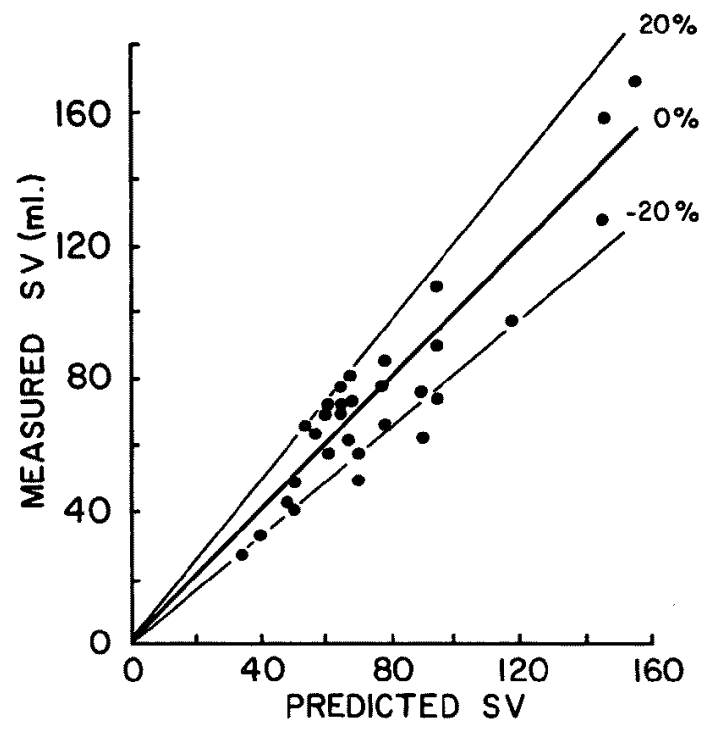

Fig. 3. Most of the predicted SV's determined from the regression equation were within $20 \%$ of the measured SV with equal scatter about the line of identity.
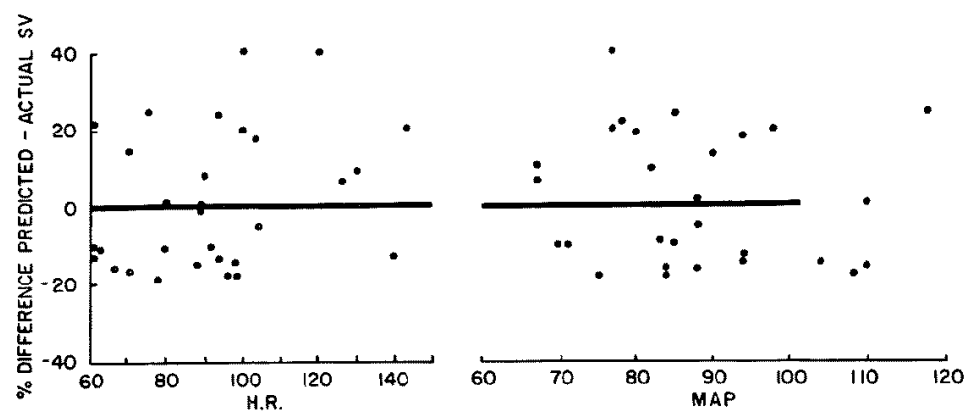

Fig. 4. A comparison of the measured-predicted stroke volume difference showed that heart rate and mean arterial pressure did not influence the ratio-SV relationship.

An example of a record obtained during infusion is shown in Fig. 5. As the stroke volume is increased by rapid infusion of blood into the animal's right atrium, there is progressive shortening of the isovolumetric and lengthening of the ejection intervals.

A comparison of ET and ICT to SV is illustrated in Fig. 6-a. In contrast to the human data, a significant correlation was found between ET and $\mathrm{SV}(\mathrm{r}=0.73)$. The ICT was inversely related to stroke volume with a correlation similar to that found in the human $(r=0.77)$. The ET-ICT ratio (Fig. 7) had a direct relationship to SV with an improved correlation over the 


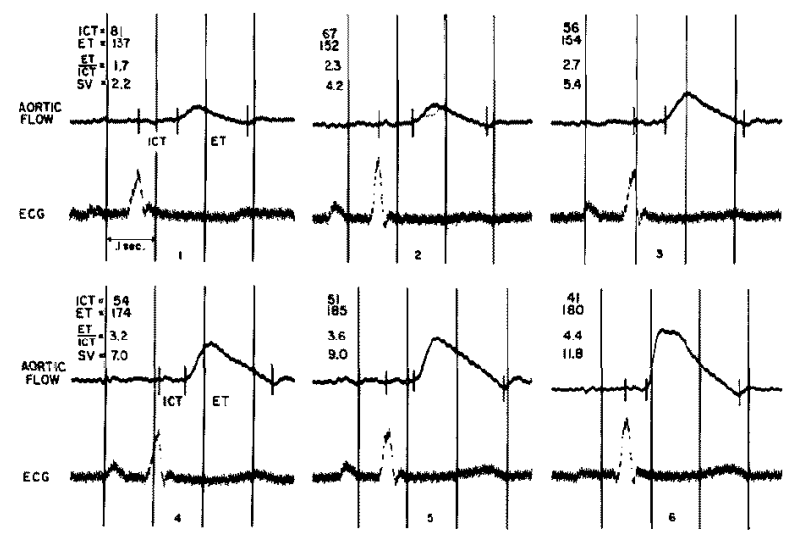

Fig. 5. An example of a flowmeter record obtained from an animal. Note the prolongation of ejection time (ET) and abbreviation of the isovolumetric contraction period (ICT) as stroke volume is augmented by infusing blood into the right atrium.
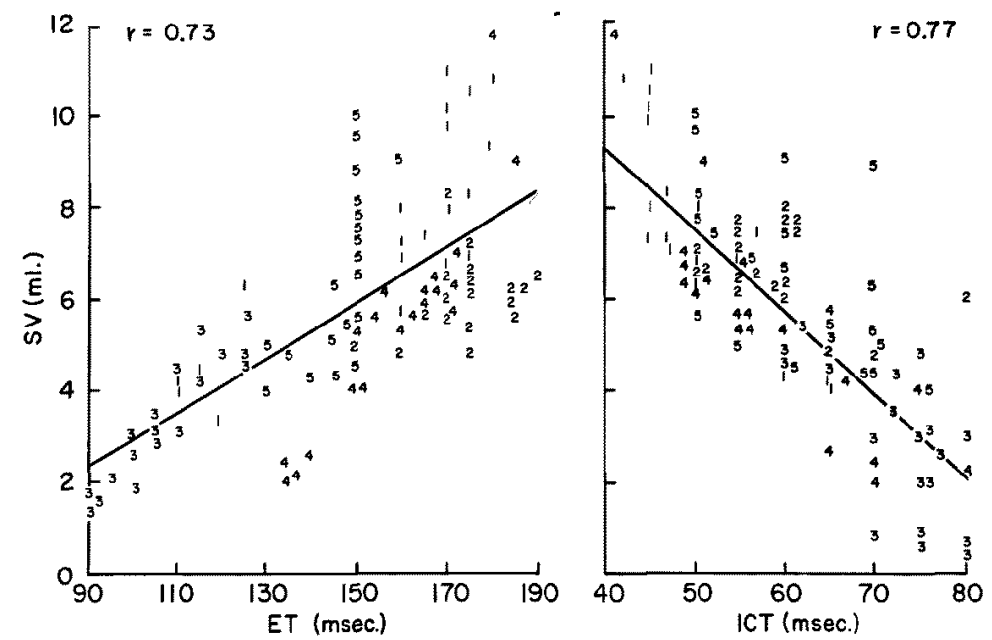

Fig. 6. Both ET and ICT were significantly related to SV in the animal experiments.

use of either interval independently $(r=0.86)$.

The measured and estimated stroke volumes based on the formula $\mathrm{SV}=2.53(\mathrm{ET} / \mathrm{ICT})-0.82$ are compared in Fig. 8 . Slightly more scatter was found than in the human data; however, most predicted SV's fell within $20 \%$ of the actual SV. As in the human, heart rate and blood pressure alterations did not appear to influence the ET/ICT ratio-stroke volume relationship (see data). 


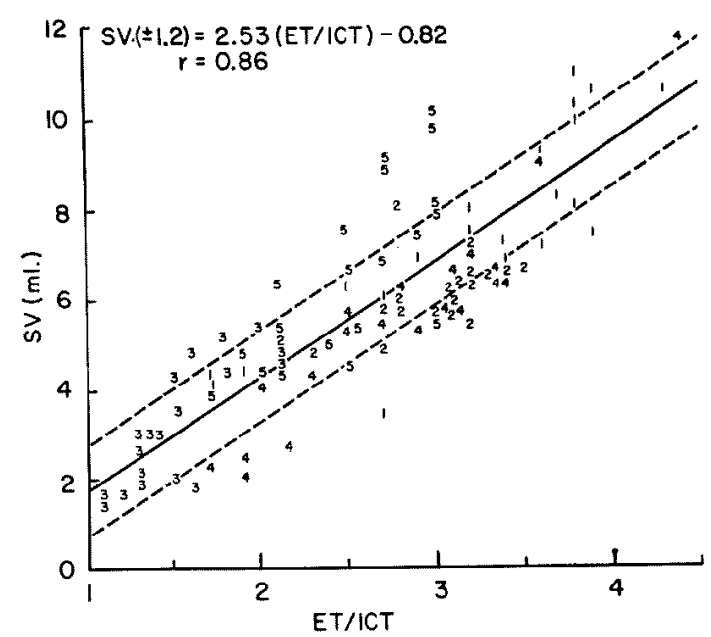

Fig. 7. The ET/ICT ratio showed an improved correlation with SV over the intervals alone.

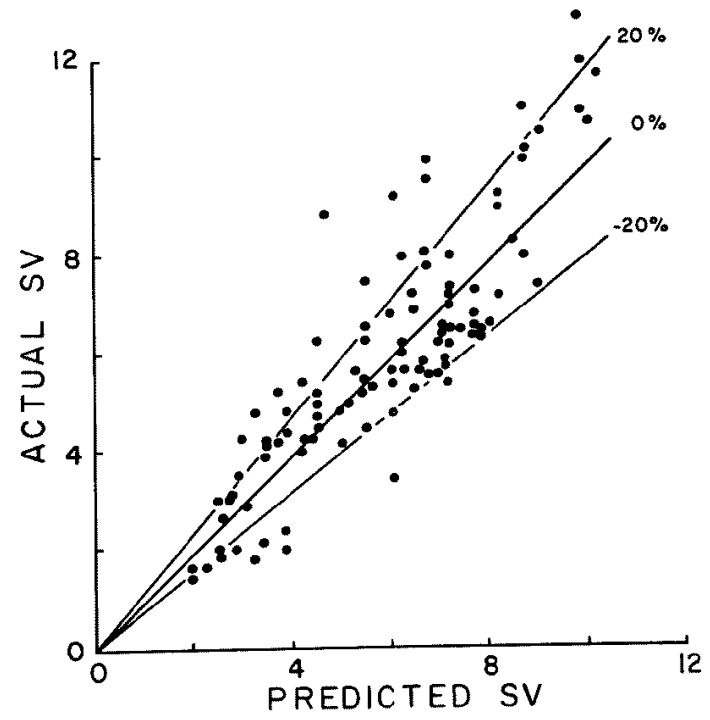

Fig. 8. A comparison of measured SV and SV obtained by the regression formula showed equal scatter about the line of identity with most predicted SV's within $20 \%$ of the actual SV.

\section{Discussion}

Investigations relating the duration of ventricular phases to stroke volume have largely been performed on the experimental animal, relatively few having been obtained in man. 
Wiggers, ${ }^{5)}$ studying the intact dog heart, found that ICT was diminished by factors which increased the stroke volume (augmented venous return or end diastolic pressure), while the ejection period was prolonged. Similar observations were made on the isolated dog heart by Katz and Feil. ${ }^{2}$ Wallace, et al.4) confirmed that ICT was inversely and ET directly related to stroke volume and concluded that, because of these opposing variations, total systole remained relatively constant even while stroke volume underwent marked variations. In man, Weissler, Peeler and Roehill ${ }^{12}$ ) have found a direct relationship between ejection time and stroke volume at rest for both the failing and non-failing heart. Jones and Foster ${ }^{9}$ however, when examining these relationships both at rest and exercise, found that the ejection phase was only slightly influenced by stroke volume.

These investigations indicate that ICT is diminished by those factors which increase stroke volume. The relationship of ET to SV, however, varies with the experimental condition. Simple expansion of blood volume, as in heart-lung studies, results in a direct ET-SV relationship, but when cardiac contractility is altered, as occurs in exercise, the ejection period can be diminished even though stroke volume is unchanged or even increased. ET may then be unrelated or inversely related to SV. For ET to be correlated with $\mathrm{SV}$ under all conditions, compensation for altered contractility must be made. Since ICT is in large part a function of the rate of ventricular pressure rise, its duration can be used as an index of contractility. ${ }^{6), 13 \text { ) }}$ By using ICT in the denominator of the ratio ET/ICT, the ejection interval is corrected for changes in contractility. The high correlation of the ratio with stroke volume in the human, despite the independence of ET and SV may thus be explained. Where ET is inversely related to $\mathrm{SV}$, the ratio may also be applicable, for if the percentage decrease of ICT is greater than that of ET, an increased ratio will result. Since the validity of the ratio is based on a true isovolumetric contraction and an ejection phase in which forward ventricular outflow represents the total stroke volume, the method would not be applicable to conditions of valvular insufficiency, shunts, etc.

It is certain that there are other factors not considered here which modify the interval-SV relationship. This is evident from the animal data where stroke volume could change independently of the intervals. That heart rate did not account for this scatter is not surprising, since ET and HR are highly correlated and thus any effects of heart rate are manifested through the duration of ET. The absence of a blood pressure effect in the human is not understood, although in the animal, the rigidity of the experimental condition (infusion of blood) may account for this finding. Further study is required to test the importance of arterial pressure, since it reflects peripheral resistance and should 
thus influence the ratio-SV correlation.

Several of the human subjects in this study manifested unusual ventricular hemodynamics: subject 18 had a cardiac output of approximately $2 \mathrm{~L}$. per min. and subject 12 exhibited a heart rate of 140 beats per min. While some question can be raised as to the normalcy of these individuals, their intervalSV relationships were not different from the other subjects in this study.

The quadratic regression equation obtained from the human data is highly dependent upon the inclusion of three stroke volumes from one subject. For this reason, a linear regression analysis was performed on the data exclusive of these three values. While the correlation coefficient of the linear equation was reduced from 0.92 to 0.86 , the standard deviation after regression (SV= 14.44 (ratio) +0.51 ) varies with the quadratic equation a maximum of only $5 \%$ between stroke volumes of 35 and $100 \mathrm{ml}$. The quadratic equation does not provide for stroke volumes below $27 \mathrm{ml}$. and may not be applicable to states of severely depressed circulation. The linear equation, however, while adequate for low stroke volumes, most likely underestimates at levels over $100 \mathrm{ml}$. and would not be useful in conditions of severe stress.

Despite these limitations, the correlations were sufficiently high to justify use of the ET-ICT ratio for the prediction of stroke volume in the intact left heart under avcrage conditions. Better understanding of other factors involved may extend the usefulness of this method.

\section{REFERENCES}

1. Frank, O.: Am. Heart J. 58: 282, 1959.

2. Katz, L. N. and Feil, H. S.: Arch. Int. Med. 32: 672, 1923.

3. Remington, J. W., Hamilton, W. F., and Ahlquist, P. R.: Am. J. Physiol. 6: 1954, 1948.

4. Wallace, A. G., Mitchell, H. J., Skinner, S. N., and Sarnoff, J. S.: Circulat. Res. 12: 6, 1963.

5. Wiggers, C. J.: Am. J. Physiol. 56-57: 439, 1921.

6. Reeves, T. and Hener, J.: Am. Heart J. 60: 745, 1960.

7. Eddleman, E. E., Jr., Willis, K., and Heyer, H.: Am. Heart J. 62: 367, 1961.

8. Braunwald, E., Sarnoff, S. J., and Stainsby, W. N.: Circulat. Res. 6: 319, 1958.

9. Jones, W. B. and Foster, G. L.: J. Appl. Physiol. 19: 279, 1964.

10. Blumberger, K.: Klin. Wchnschr. 20:681 and 708, 1941.

11. Agress, C. M., Wcgncr, S., and Nakakura, S.: Physiologist 8: 3, 1965.

12. Weissler, A. M., Peeler, R. G., and Roehill, W. H., Jr.: Am. Heart J. 62: 367, 1961.

13. Sambhi, M. B.: Am. J. Cardiol. 6: 1042, 1960. 